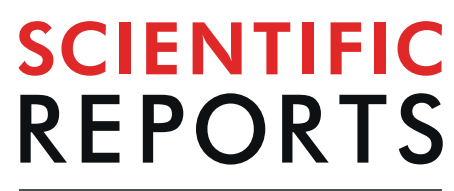

natureresearch

Published online: 20 November 2019

\title{
Author Correction: A New Hadrosaurine (Dinosauria: Hadrosauridae) from the Marine Deposits of the Late Cretaceous Hakobuchi Formation, Yezo Group, Japan
}

\author{
Yoshitsugu Kobayashi, Tomohiro Nishimura, Ryuji Takasaki $₫$, Kentaro Chiba, \\ Anthony R. Fiorillo, Kohei Tanaka, Tsogtbaatar Chinzorig (D, Tamaki Sato \& Kazuhiko Sakurai \\ Correction to: Scientific Reports https://doi.org/10.1038/s41598-019-48607-1, published online 05 September \\ 2019
}

The original version of this Article did not meet the requirement of the amendment of Article 8.5.3 of the International Code of Zoological Nomenclature ${ }^{1}$. To fully meet the amended provisions of the Code, the following Nomenclatural Acts have been added to the Materials and Methods section:

Nomenclatural Acts. The electronic edition of this article conforms to the requirements of the amended International Code of Zoological Nomenclature, and hence the new names contained herein are available under that Code from the electronic edition of this article. This published work and the nomenclatural acts it contains have been registered in ZooBank, the online registration system for the ICZN. The ZooBank LSIDs (Life Science Identifiers) can be resolved and the associated information viewed through any standard web browser by appending the LSID to the prefix "http://zoobank.org/". The LSID for this publication is: urn:lsid:zoobank. org:act:FC9D5C4F-AF5E-4FB5-9D45-EA4E91229BDC.

\section{Reference}

1. Amendment of Articles 8, 9, 10, 21 and 78 of the International Code of Zoological Nomenclature to expand and refine methods of publication. ZooKeys 219, 1-10, https://doi.org/10.3897/zookeys.219.3944 (2012).

\begin{abstract}
(c) (i) Open Access This article is licensed under a Creative Commons Attribution 4.0 International License, which permits use, sharing, adaptation, distribution and reproduction in any medium or format, as long as you give appropriate credit to the original author(s) and the source, provide a link to the Creative Commons license, and indicate if changes were made. The images or other third party material in this article are included in the article's Creative Commons license, unless indicated otherwise in a credit line to the material. If material is not included in the article's Creative Commons license and your intended use is not permitted by statutory regulation or exceeds the permitted use, you will need to obtain permission directly from the copyright holder. To view a copy of this license, visit http://creativecommons.org/licenses/by/4.0/.
\end{abstract}

(C) The Author(s) 2019 